\title{
Microbiological characterization and functionality of set-type yogurt fermented with potential prebiotic substrates Cudrania tricuspidata and Morus alba L. leaf extracts
}

\author{
Nam Su Oh, ${ }^{* 1}$ Ji Young Lee, ${ }^{*} \dagger^{1}$ Jae Yeon Joung, ${ }^{*}$ Kyung Su Kim, ${ }^{*}$ Yong Kook Shin, ${ }^{*}$ Kwang-Won Lee, $\dagger$ \\ Sae Hun Kim,† Sangnam Oh, $\ddagger$ and Younghoon Kim $\ddagger^{2}$ \\ ${ }^{*}$ R\&D Center, Seoul Dairy Cooperative, Ansan, Gyeonggi 425-839, South Korea \\ †Department of Biotechnology, College of Life Sciences and Biotechnology, Korea University, Seoul 136-713, South Korea \\ ‡Department of Animal Science and Institute of Milk Genomics, Chonbuk National University, Jeonju, 561-756, Korea
}

\begin{abstract}
The objective of this study was to investigate the effect of 2 plant leaf extracts on fermentation mechanisms and health-promoting activities and their potential as a nutraceutical prebiotics ingredient for application in dairy products. The individual active phenolic compounds in the plant extract-supplemented milk and yogurts were also identified. Compared with control fermentation, the plant extracts significantly increased the growth and acidification rate of Streptococcus thermophilus and Lactobacillus delbrueckii ssp. bulgaricus. In particular, plant extract components, including monosaccharides, formic acid, and hydroxycinnamic acid, such as neo-chlorogenic, chlorogenic, and caffeic acid, together play a stimulatory role and cause this beneficial effect on the growth of yogurt culture bacteria through fermentation. In addition, supplementation with the plant extracts enhanced antioxidant activities with increased total phenolic contents, especially the highest antioxidant activity was observed in yogurt supplemented with Cudrania tricuspidata leaf extract.
\end{abstract}

Key words: yogurt, fermentation, phenolic compounds, antioxidant activity

\section{INTRODUCTION}

Yogurt containing pro- and prebiotics is known to have many beneficial effects such as strengthening the immune system and intestinal system, assisting lactose digestion, and alleviating inflammatory bowel disease and allergies (Adolfsson et al., 2004). In addition to these health benefits, the physical properties,

Received December 23, 2015.

Accepted March 28, 2016.

${ }^{1}$ These authors contributed equally to this study.

${ }^{2}$ Corresponding author: ykeys2584@jbnu.ac.kr appearance, and flavor of the yogurt are important factors for consumer acceptability. Texture, flavor, acid production from the starter cultures, bacteria during fermentation, and even storage care can be modified by altering the process conditions or by adding supplementary ingredients. The ingredients that determine the nutritional value or technical applications (or both) of yogurts include milk protein (Peng et al., 2009), prebiotics (Bruno et al., 2002), and plants (Amirdivani and Baba, 2011). Fructooligosaccharide, galactooligosaccharide, and isomaltooligosaccharide (Manning and Gibson, 2004) are widely used prebiotics that enhance the activity of gut microorganisms. Recently, research efforts have been focused on finding prebiotics from plant extracts, but only a few studies have shown the functional and prebiotic properties of plant extracts in yogurt processing. Plant extracts have been shown to possess health-promoting properties such as antimicrobial and antioxidant effects. Therefore, new prebiotics derived from plant extracts that stimulate the growth of lactic acid bacteria (LAB) are needed. In a search for new natural prebiotic sources for yogurt production, we manufactured yogurts supplemented with functional plant extracts of Cudrania tricuspidata leaves (CT) and Morus alba L. leaves (MA), and studied various functional properties of these yogurts.

Cudrania tricuspidata, which has beneficial properties such as antimicrobial, anti-inflammatory, and antitumor effects and $\alpha$-glucosidase inhibitory activity (Park et al., 2006), is one of the most ubiquitous traditional plant remedies in Asia. Morus alba L. is a deciduous tree that is distributed throughout Asia, Africa, Europe, and South and North America and found in a wide range of tropical areas (Srivastava et al., 2006). Tree bark, fruits, and leaves of M. alba have been used as natural medicines and the leaves are used as tea infusion in Asian countries (Katsube et al., 2009). Extensive reports are available on the inhibitory effect of watersoluble C. tricuspidata and M. alba leaf extracts on lipid 
peroxidative formation (Cha et al., 2000) and on the antibacterial efficacy of C. tricuspidata fruit essential oil (Bajpai et al., 2013). However, the use of these 2 plant leaf extracts in food has hardly been studied.

Previously, our group has screened aqueous extracts from 100 herb species to test their prebiotic activity by determining oligosaccharides, water-soluble dietary fiber, and total phenol contents (data not shown). On the basis of the results, 2 plant extracts were selected for this study, which may serve as a good source of functional nutrients and prebiotics for yogurt starter cultures to improve microbial and chemical properties. Here, we investigated the effects of yogurt supplementation with the extracts on the acidification kinetics, growth of yogurt starter cultures, and fermentation mechanisms during fermentation. In addition, the phenolic compounds in the plant extract-supplemented yogurts were profiled, and the antioxidant properties of the final product immediately after production and during $28 \mathrm{~d}$ of refrigerated storage were evaluated to investigate the effects of the plant extracts on fermentation.

\section{MATERIALS AND METHODS}

\section{Plant Extracts}

The CT and MA were obtained from the local market (Sunchang, Jeollabuk-Do, South Korea). One hundred grams of leaves was washed and then soaked in distilled water $(1,000 \mathrm{~mL})$ in a water bath $\left(100^{\circ} \mathrm{C}\right)$ with occasional shaking for $9 \mathrm{~h}$ for extraction. Then, the leaf extract was filtered through filter paper. The clear solution was concentrated by evaporation to dryness under vacuum at temperatures not higher than $50^{\circ} \mathrm{C}$. The concentrated plant extracts were freeze-dried before use in yogurt production.

\section{Preparation of Fermented Milks Supplemented With Plant Extracts}

The powdered plant extracts $[0.2 \%(\mathrm{~g} / \mathrm{g})]$ were added to prewarmed $\left(60^{\circ} \mathrm{C}\right)$ milk, and the mixtures were pasteurized $\left(85^{\circ} \mathrm{C}, 15 \mathrm{~min}\right)$ and cooled to $41^{\circ} \mathrm{C}$. Milks with and without plant extract were inoculated with a commercial yogurt starter culture containing Streptococcus thermophilus (ST-BODY-1) and Lactobacillus delbrueckii ssp. bulgaricus (LB-12) direct vat set (DVS) cultures (Chr. Hansen, Hørsholm, Denmark). The inoculum was prepared using direct vat set cultures at concentration of $0.002 \mathrm{~g}$ of starter culture (each per liter). The mixtures were incubated at $41^{\circ} \mathrm{C}$ until a $\mathrm{pH}$ of 4.5 was achieved. Samples were collected directly after production and after $7,14,21$, and $28 \mathrm{~d}$ of refrigerated storage at $4^{\circ} \mathrm{C}$. The yogurt without added plant extracts was used as control in this study. All samples were lyophilize and stored at $-20^{\circ} \mathrm{C}$ before analysis.

\section{Kinetic Parameters}

Each fermentation, performed in 3 replicates, was monitored as described previously (Oliveira et al., $2009)$. The acidification rate $\left(\mathbf{V}_{\max }\right)$ was calculated as the time variation of $\mathrm{pH}(\mathrm{dpH} / \mathrm{dt})$ and expressed as $10^{-3} \mathrm{pH}$ units/min. During the fermentation period, the following kinetic parameters were calculated: (1) $\mathbf{t}_{\max }$ (h), time at which $\mathrm{V}_{\max }$ was reached; (2) $\mathbf{t}_{\mathrm{pH}} \mathbf{5 . 0}(\mathrm{h})$, time to reach $\mathrm{pH} 5.0$; and $(3) \mathbf{t}_{\mathbf{f}}(\mathrm{h})$, time to complete the fermentation.

\section{Viability of Starter Cultures}

For each run of the experimental design, samples were analyzed immediately after fermentation and after 4 wk of storage at $4^{\circ} \mathrm{C}$. Streptococcus thermophilus was counted on M17 agar (Oxoid, Basingstoke, UK) plates after aerobic incubation at $37^{\circ} \mathrm{C}$ for $48 \mathrm{~h}$. Lactobacillus delbrueckii ssp. bulgaricus was enumerated on MRS (Difco Laboratories, Detroit, MI) at pH 5.2 with acetic acid after anaerobic incubation at $45^{\circ} \mathrm{C}$ for $72 \mathrm{~h}$ in an anaerobic jar with anaerobe gas packs (MGC, Tokyo, Japan; Ravula and Shah, 1998; Tharmaraj and Shah, 2003).

\section{Analysis of Sugars and Organic Acids}

Sugars (fructose, glucose, galactose, and lactose) in the plant yogurts were analyzed by using HPLC (Agilent Technologies, Waldbronn, Germany) based on AOAC Official Methods 980.13 and 972.16 (AOAC International, 2012).

All organic acid standards (citric acid, lactic acid, propionic acid, pyruvic acid, and formic acid) were supplied by Sigma Chemical Co. (St. Louis, MO). Organic acids in the plant yogurts were determined following procedure reported by Donkor et al. (2005). Briefly, the plant yogurt samples $(2 \mathrm{~g})$ were mixed with 0.005 $N \mathrm{H}_{2} \mathrm{SO}_{4}(6 \mathrm{~mL})$. The mixture was centrifuged at 5,000 $\times g$ for 10 min and the supernatant was filtered with $0.2-\mu \mathrm{m}$ pore size membrane filter. The separation of organic acids was achieved using HPLC fitted with Aminex HPX-87C column (Bio-Rad, Hercules, CA) maintained at $50^{\circ} \mathrm{C}$. The mobile phase was $0.005 \mathrm{~N}$ $\mathrm{H}_{2} \mathrm{SO}_{4}$ with a flow rate $0.6 \mathrm{~mL} / \mathrm{min}$. Quantification of organic acids was determined from the standard curves of solutions of known concentrations. 


\section{Ultra-Performance Liquid Chromatography-MS/MS Analysis of Phenolic Compounds}

For extraction of phenolic compounds from the plant yogurts, lyophilized yogurt samples $(2 \mathrm{~g})$ were homogenized with $14 \mathrm{~mL}$ of $50 \%$ ethanol containing $0.05 \mathrm{M} \mathrm{H}_{3} \mathrm{PO}_{4}$ in water. The extracts were sonicated in an ultrasonic bath at room temperature for $20 \mathrm{~min}$ and centrifuged at $5,180 \times g$ for $30 \mathrm{~min}$. The supernatant was filtered through a $0.2-\mu \mathrm{m}$ pore size membrane filter into HPLC vials for analysis.

The ultra-performance liquid chromatography-MS/ MS analyses were carried out using an ACQUITY Ultra Performance Liquid Chromatography system (Waters, Milford, MA) equipped with a Z-spray electrospray ionization source and ZEVO TQ iontrap (MS/ MS; Waters) operating in negative mode. MassLynx software (version 4.0, Waters) was used to control the instruments, and for data acquisition and processing. Sample solutions were injected into a reversed-phase column (BEH C18, $1.7 \mu \mathrm{m}, 2.1 \times 150 \mathrm{~mm}$, Waters), which was maintained at $30^{\circ} \mathrm{C}$. The separation was executed with a mobile phase consisting of $0.1 \%$ formic acid in water (mobile phase A) and $0.1 \%$ formic acid in acetonitrile (mobile phase B) with linear gradient elution performed as follows: 0 to $9.8 \mathrm{~min}, 8 \% \mathrm{~B} ; 9.8$ to $21.80 \mathrm{~min}, 15 \%$ B; 21.8 to $23.8 \mathrm{~min}, 22 \%$ B; 23.8 to 27.8 min, $40 \%$ B; 27.8 to 28.2 min, hold on $40 \% \mathrm{~B}$; and 28.2 to $29.8 \mathrm{~min}$, back to $8 \% \mathrm{~B}$. The linear binary gradient was set to a flow rate of $0.2 \mathrm{~mL} / \mathrm{min}$ and total run time was $29.8 \mathrm{~min}$. Ten microliters of sample was injected into the electrospray source (source temperature $150^{\circ} \mathrm{C}$, desolvation temperature $360^{\circ} \mathrm{C}$, capillary voltage 2.5 $\mathrm{kV}$, cone voltage $25 \mathrm{~V}$ ). Argon was used as collision gas (collision energy $25 \mathrm{eV}$ at the start).

\section{Antioxidant Capacity}

Total phenolic compounds were determined by an assay from Maksimović et al. (2005). Total phenolic contents (TPC) were expressed as micrograms of gallic acid equivalent $(\mathbf{G A E}) / \mathrm{mL}$ using a regression of known concentrations of gallic acid, which was determined every time total phenolic assay was carried out. Also, we evaluated the antioxidant activities of yogurt by 1,1-diphenyl-2-picrylhydrazyl (DPPH) radical scavenging activity, ferric-reducing antioxidant power assay, and 2,2'-azino-bis(3-ethylbenzothiazoline-6-sulfonic acid) diammonium salt (ABTS) radical scavenging activity using the method of Oh et al. (2013).

\section{Statistical Analysis}

All data were expressed as means \pm SD. Statistical significance for the differences between the groups was assessed using Duncan's multiple range tests. SAS software version 9.2 (SAS Institute Inc., Cary, NC) was used to perform all statistical tests. Values of $P<0.05$ were considered to indicate a significant difference.

\section{RESULTS AND DISCUSSION}

\section{Fermentation Kinetics and Culture Growth During Fermentation}

The acidification kinetic parameters of the 2 plant yogurts are presented in Table 1. Both plant extracts significantly accelerated yogurt acidification. The addition of CT and MA increased $\mathrm{V}_{\max }$ by 57 and $75 \%$, respectively, whereas $t_{\max }$ of the CT-supplemented yogurt was the shortest. The fermentation was more rapidly completed in the plant extract-supplemented samples than in the control. Especially, $t_{\mathrm{pH}} 5.0$ and $t_{\mathrm{f}}$ were slightly shorter in CT-supplemented than in MA-supplemented yogurt. These results showed that CT and MA significantly accelerated acidification and fermentation. Similarly, Amirdivani and Baba (2011) reported that fermentation with herbs enhanced the metabolic activity of yogurt bacteria and that the $\mathrm{pH}$ was decreased due to increased production of organic acids by LAB. According to Oliveira et al. (2009), coculture of $S$. thermophilus and L. delbrueckii ssp. bulgaricus was the best for yogurt preparation; however, in this study, the prebiotic effect of nondigestible oligosaccharides (such as maltodextrin, polydextrose, and oligofructose) on probiotics was evaluated. Multiple other studies have reported that various commercial prebiotics such as inulin, maltodextrin, oligofructose, and polydextrose accelerated acidification of the yogurt and reduced the fermentation time (Jaya and Das, 2004). Here, we tested the effects of 2 novel prebiotic ingredients from plant sources on yogurt fermentation kinetics. Our results indicated that CT and MA might be appropriate prebiotic ingredients for yogurt preparation in terms of acidification and fermentation time. The viability of $S$. thermophilus and L. delbrueckii ssp. bulgaricus in the yogurts during fermentation is presented in Figure 1. In agreement with the results for acidification kinetics, both yogurts supplemented with plant extracts showed a more rapid increase in microbe counts than the control yogurt. The viabilities of $S$. thermophilus and L. delbrueckii ssp. bulgaricus in all yogurts increased with 2.61 to $2.95 \log \mathrm{cfu} / \mathrm{mL}$ and with 0.69 to 1.14 $\log \mathrm{cfu} / \mathrm{mL}$, respectively, during fermentation. The $S$. thermophilus counts in the CT- and MA-supplemented yogurts were significantly higher than in the control, whereas the viability of $L$. delbrueckii ssp. bulgaricus at the end of fermentation was in the following order: control $>$ MA $>$ CT. After approximately $4 \mathrm{~h}$ of fermenta- 
Table 1. Acidification kinetic parameters of the yogurts supplemented with the plant extracts ${ }^{1}$

\begin{tabular}{|c|c|c|c|}
\hline \multirow[b]{2}{*}{ Kinetic parameter ${ }^{2}$} & \multicolumn{3}{|c|}{ Type of yogurt } \\
\hline & Control & $\mathrm{CT}$ & MA \\
\hline $\begin{array}{l}\mathrm{V}_{\max }\left(10^{-3} \mathrm{pH} \text { units/min }\right) \\
\mathrm{t}_{\max }(\mathrm{h}) \\
\mathrm{t}_{\mathrm{pH}}(\mathrm{h}) \\
\mathrm{t}_{\mathrm{f}}(\mathrm{h})\end{array}$ & $\begin{array}{r}8.33 \pm 0.83^{\mathrm{c}} \\
10.67 \pm 0.58^{\mathrm{a}} \\
10.71 \pm 0.16^{\mathrm{a}} \\
11.48 \pm 0.49^{\mathrm{a}}\end{array}$ & $\begin{array}{r}12.83 \pm 0.50^{\mathrm{b}} \\
3.67 \pm 0.58^{\mathrm{c}} \\
4.31 \pm 0.05^{\mathrm{c}} \\
5.80 \pm 0.18^{\mathrm{b}}\end{array}$ & $\begin{aligned} 14.58 & \pm 0.25^{\mathrm{a}} \\
4.00 & \pm 0.00^{\mathrm{b}} \\
4.72 & \pm 0.06^{\mathrm{b}} \\
5.95 & \pm 0.14^{\mathrm{b}}\end{aligned}$ \\
\hline
\end{tabular}

${ }^{\mathrm{a}-c}$ Different letters within a row denote significant differences $(P \leq 0.05)$.

${ }^{1}$ Values are presented as the mean $\pm \mathrm{SD}(\mathrm{n}=3) . \mathrm{CT}=$ Cudrania tricuspidata-supplemented yogurt; MA = Morus alba-supplemented yogurt.

${ }^{2} \mathrm{~V}_{\max }=$ acidification rate; $\mathrm{t}_{\max }=$ time at which $\mathrm{V}_{\max }$ was reached; $\mathrm{t}_{\mathrm{pH} 5.0}=$ time to reach $\mathrm{pH} 5.0$; and $(3) \mathrm{t}_{\mathrm{f}}=$ time to complete the fermentation.

tion, the $\mathrm{V}_{\max }$ of the plant yogurts was higher than that of the control yogurt, consistent with the acidification kinetics. In particular, the MA-supplemented yogurt showed the highest counts of $S$. thermophilus and $L$. delbrueckii ssp. bulgaricus with $8.86 \pm 0.02 \mathrm{log} \mathrm{cfu} /$ $\mathrm{mL}$ and $6.21 \pm 0.01 \log \mathrm{cfu} / \mathrm{mL}$, respectively, among the yogurts with added plant extracts. Based on these results, we conclude that the plant extracts have potential for application in yogurt manufacture as prebiotics to shorten fermentation time, increase the viability of starter cultures, or to target beneficial LAB.

\section{Sugar Contents}

The concentrations of various sugars in the yogurts are displayed in Table 2. Before fermentation, the concentration of lactose in unfermented samples ranged from $53.02 \pm 0.02 \mathrm{mg} / \mathrm{g}$ to $53.50 \pm 0.19 \mathrm{mg} / \mathrm{g}$. It considerably decreased during fermentation, ranging from $35.60 \pm 0.08 \mathrm{mg} / \mathrm{g}$ to $37.42 \pm 0.04 \mathrm{mg} / \mathrm{g}$, without significant differences between the yogurt samples. The concentrations of galactose and glucose increased at the end of fermentation. Lactose is the primary carbon and energy source for many LAB, and it is metabolized to galactose and glucose during fermentation. Further, before fermentation, the concentration of fructose in the CT- and MA-supplemented samples was $0.18 \pm$ $0.01 \mathrm{mg} / \mathrm{g}$ and $0.10 \pm 0.01 \mathrm{mg} / \mathrm{g}$, respectively, whereas fructose was not detected in the control sample. At the end of fermentation, its concentration in the CT- and MA-supplemented yogurt was decreased to $0.041 \pm$ $0.00 \mathrm{mg} / \mathrm{g}$ and $0.037 \pm 0.00 \mathrm{mg} / \mathrm{g}$, respectively. This result indicated that fructose present in the $\mathrm{CT}$ and MA extracts may have served as an additional carbon source for yogurt fermentation. Because of the higher utilization rate of fructose in CT-supplemented yogurt (77\%) than in MA-supplemented yogurt (61\%), CT may enhance the metabolic activities of the starter cultures, resulting in dramatically shorter fermentation time than that for control yogurt. It has been reported that metabolism of sugars by LAB varies from strain to strain and depends on the substrates and fermentation time (Amoroso et al., 1989).

\section{Organic Acid Contents}

The use of the 2 organisms $S$. thermophilus and $L$. delbrueckii ssp. bulgaricus is beneficial for the production of fermented milk worldwide because of their synergistic interaction or symbiotic relationship (Roginski et al., 2003). The organic acid contents in the plant yogurts produced using these 2 organisms are displayed in Table 3. After fermentation, a significant change in the organic acid contents in the yogurts supplemented with the plant extracts was detected. As noted by Vedamuthu (1977), organic acids, such as lactic acid and pyruvic acid, and acetoin, diacetyl, ethanol, and $\mathrm{CO}_{2}$ are the major end products of LAB carbohydrate metabolism. A small amount of formic acid was present in unfermented control milk. However, the amount of formic acid in unfermented milk supplemented with the plant extracts was higher than in control milk. In particular, CT-supplemented unfermented milk had the highest formic acid levels $(5.03 \pm 0.08 \mathrm{mg} / \mathrm{g})$ among the samples, and $94.8 \%$ of the intrinsic formic acid in CT-supplemented unfermented milk was used during the production of plant yogurt, which enhanced the viability of the starter culture. The reason for this result may be that the formic acid in the plant extracts stimulated LAB fermentation. According to Roginski et al. (2003), L. delbrueckii ssp. bulgaricus has more proteolytic activity than $S$. thermophilus. Peptides and AA produced by the proteolytic enzymes of $L$. delbrueckii ssp. bulgaricus stimulate the growth of $S$. thermophilus, and the formic acid generated by $S$. thermophilus reactivates L. delbrueckii ssp. bulgaricus.

Lactic acid is a common end product of LAB fermentation, and its level increased significantly more in CTand MA-supplemented yogurt than in control yogurt, to $6.91 \pm 0.01 \mathrm{mg} / \mathrm{g}$ and $7.11 \pm 0.02 \mathrm{mg} / \mathrm{g}$, respectively. 

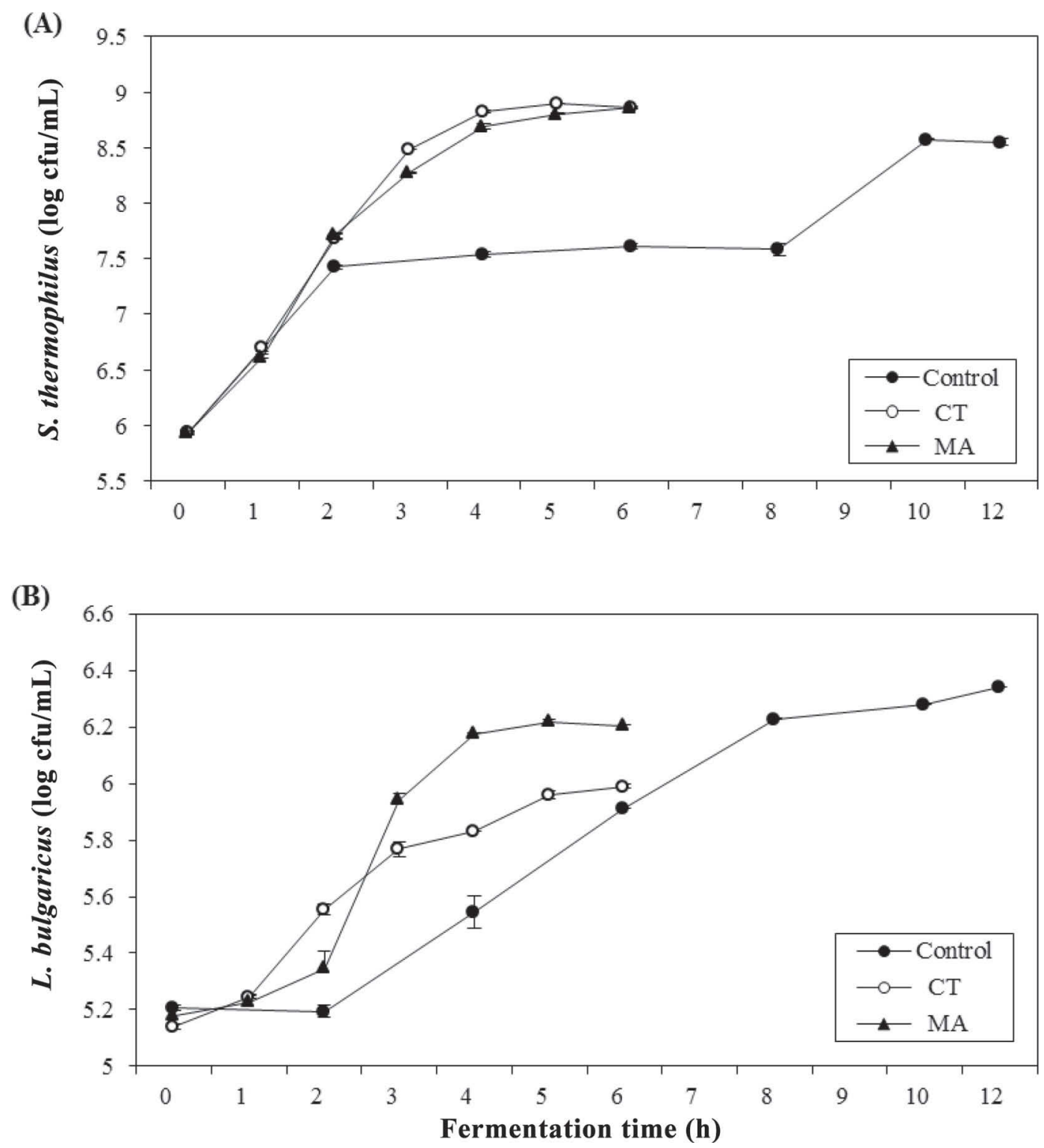

Figure 1. Changes in (A) Streptococcus thermophilus counts and (B) Lactobacillus bulgaricus counts of the plant yogurts during fermentation. The results are presented as the mean $\pm \mathrm{SD}(\mathrm{n}=3)$. $\mathrm{CT}=$ Cudrania tricuspidata-supplemented yogurt; MA $=$ Morus alba-supplemented yogurt

Table 2. Sugar contents of the yogurts supplemented with the plant extracts ${ }^{1}$

\begin{tabular}{|c|c|c|c|c|c|c|}
\hline \multirow[b]{2}{*}{ Sugar } & \multicolumn{2}{|c|}{ Control } & \multicolumn{2}{|c|}{$\mathrm{CT}$} & \multicolumn{2}{|c|}{ MA } \\
\hline & $\begin{array}{c}\text { Before } \\
\text { fermentation }\end{array}$ & $\begin{array}{c}\text { After } \\
\text { fermentation }\end{array}$ & $\begin{array}{c}\text { Before } \\
\text { fermentation }\end{array}$ & $\begin{array}{c}\text { After } \\
\text { fermentation }\end{array}$ & $\begin{array}{c}\text { Before } \\
\text { fermentation }\end{array}$ & $\begin{array}{c}\text { After } \\
\text { fermentation }\end{array}$ \\
\hline Fructose (mg/g) & ND & ND & $0.18 \pm 0.01^{\mathrm{a}}$ & $0.041 \pm 0.00^{\mathrm{c}}$ & $0.10 \pm 0.01^{\mathrm{b}}$ & $0.037 \pm 0.00^{\mathrm{c}}$ \\
\hline Glucose (mg/g) & $0.11 \pm 0.01^{\mathrm{f}}$ & $0.39 \pm 0.09^{\mathrm{c}}$ & $0.26 \pm 0.01^{\mathrm{d}}$ & $0.66 \pm 0.007^{\mathrm{a}}$ & $0.17 \pm 0.08^{\mathrm{e}}$ & $0.48 \pm 0.06^{\mathrm{b}}$ \\
\hline Galactose $(\mathrm{mg} / \mathrm{g})$ & ND & $6.48 \pm 0.05^{\mathrm{b}}$ & ND & $5.17 \pm 0.07^{\mathrm{c}}$ & ND & $7.96 \pm 0.03^{\mathrm{a}}$ \\
\hline Lactose $(\mathrm{mg} / \mathrm{g})$ & $53.02 \pm 0.02^{\mathrm{a}}$ & $35.60 \pm 0.08^{\mathrm{b}}$ & $53.50 \pm 0.19^{\mathrm{a}}$ & $37.42 \pm 0.04^{\mathrm{b}}$ & $53.50 \pm 1.09^{\mathrm{a}}$ & $36.29 \pm 0.28^{\mathrm{b}}$ \\
\hline
\end{tabular}

${ }^{\mathrm{a}-\mathrm{f}}$ Different letters within a row denote significant differences $(P \leq 0.05)$.

${ }^{1}$ Values are presented as the mean $\pm \mathrm{SD}(\mathrm{n}=3)$. ND $=$ not detected. CT $=$ Cudrania tricuspidata-supplemented yogurt; MA $=$ Morus albasupplemented yogurt. 
During the manufacturing of plant yogurts, more lactic acid is generated than other organic acids. This result is consistent with the high titratable acidity (control yogurt: $0.75 \%$, CT-supplemented yogurt: $0.78 \%$, and MAsupplemented yogurt: $0.88 \%$ ). In addition, the level of pyruvic acid increased significantly in all samples after fermentation. Moreover, pyruvic acid showed the lowest level, ranging from $0.024 \pm 0.00 \mathrm{mg} / \mathrm{g}$ to $0.036 \pm 0.04$ $\mathrm{mg} / \mathrm{g}$, which may be because pyruvic acid acts as an important intermediary in various metabolic pathways. Previous studies have reported that the carbohydrate source, such as lactose, is transported across the cell membrane of LAB through the mediation of a membrane-located enzyme, and $\beta$-galactosidase then hydrolyzes the sugar to glucose and galactose. The LAB use the Embden-Meyerhof pathway to produce pyruvate and lactic acid dehydrogenase and then metabolize the pyruvate to lactic acid (Roginski et al., 2003).

As shown in Table 3, citric acid was a predominant organic acid in unfermented milk, ranging from $2.64 \pm$ $0.19 \mathrm{mg} / \mathrm{g}$ to $2.84 \pm 0.01 \mathrm{mg} / \mathrm{g}$. After fermentation, a significant decrease occurred in the citric acid contents of all yogurts: 8.8 and $12.8 \%$ of citric acid in milk was used by yogurt cultures in samples with the CT and MA extracts, respectively, compared with $3.5 \%$ in the control yogurt. The results indicated that the $\mathrm{CT}$ and MA extracts could aid fermentation and supply growth factors for yogurt production.

Adhikari et al. (2002) did not detect propionic acid in milk. Similarly, we did not find propionic acid in unfermented control milk. However, propionic acid was present in unfermented milk supplemented with the plant extracts, ranging from $0.096 \pm 0.03 \mathrm{mg} / \mathrm{g}$ to $0.10 \pm 0.00 \mathrm{mg} / \mathrm{g}$, and its level decreased after fermentation. As mentioned previously, the addition of the plant extracts for yogurt manufacturing enhanced the fermentation kinetics and culture growth. Furthermore, the organic acid produced during plant yogurt fermentation may promote volatile compounds that determine the flavor for yogurt as well as sensory characteristics.

\section{Phenolic Compound Contents}

The phenolic compound concentrations in the yogurts were evaluated throughout fermentation. Figures 2 and 3 show ultra-performance liquid chromatography-MS total ion current chromatograms of a mixed CT- and MA-supplemented yogurt. The retention times, mass spectral characteristics, and individual multiple reaction monitoring transitions used for quantifying are specified in Table 4.

After fermentation, the composition of the phenolic compounds in the CT- and MA-supplemented yogurts was similar to that in the unfermented samples; however, the amount of the individual compounds differed (Table 5). In total, 10 phenolic compounds were detected in the CT-supplemented yogurt. Both CT- and MA-supplemented yogurts contained a variety of phenolic compounds, and the most prominent compound was neo-chlorogenic acid followed by chlorogenic acid. The total contents of phenolic compounds content of the CT-supplemented yogurt significantly decreased when compared with nonfermented samples. The rate of phenolic compound utilization in CT-supplemented yogurt was higher than that in MA-supplemented yogurt (7.86 and $1.99 \%$, respectively), indicating that the starter bacteria metabolized the phenolic compounds. Especially, neo-chlorogenic acid, chlorogenic acid, and caffeic acid were the most affected during fermentation in CT-supplemented yogurt, whereas 3,4-dihydroxy-hydrocinnamic acid was slightly increased after fermentation. Degradation of chlorogenic acid by cleavage of the ester bond between caffeic acid and quinic acid results in the production of 3,4-dihydroxy-hydrocinnamic acid, suggesting that caffeic acid was reduced at the double bond (Couteau et al., 2001). One study reported the detection of 3-(3-hydroxyphenyl)-propionic acid in an in vitro mixed-culture model of human colonic microflora after 24-h fermentation, resulting from dehydroxylation of 3,4-dihydroxy-hydrocinnamic acid (Rechner et al., 2004). We did not detect this compound, likely because

Table 3. Organic acids contents of the yogurts supplemented with the plant extracts ${ }^{1}$

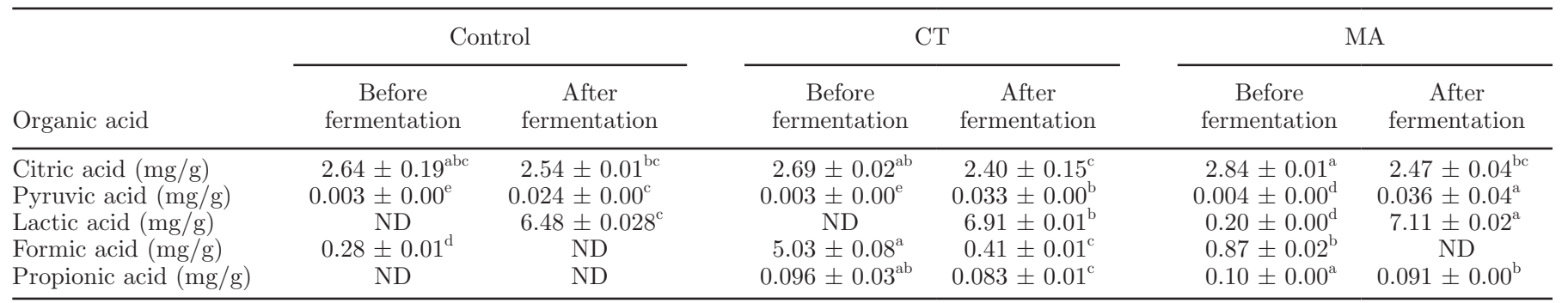

${ }^{\mathrm{a} e \mathrm{e}}$ Different letters within a row denote significant differences $(P \leq 0.05)$.

${ }^{1}$ Values are presented as the mean $\pm \mathrm{SD}(\mathrm{n}=3)$. ND = not detected. CT $=$ Cudrania tricuspidata-supplemented yogurt; MA $=$ Morus albasupplemented yogurt. 
(A)

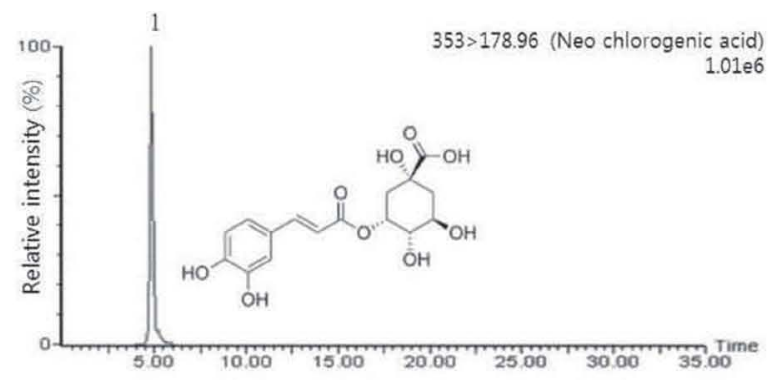

(B)

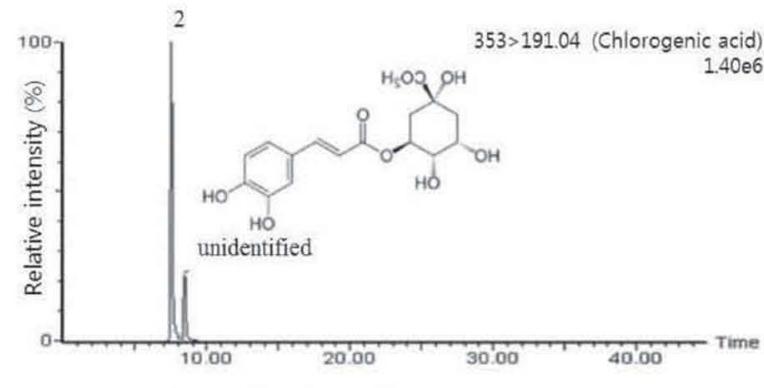

(C)

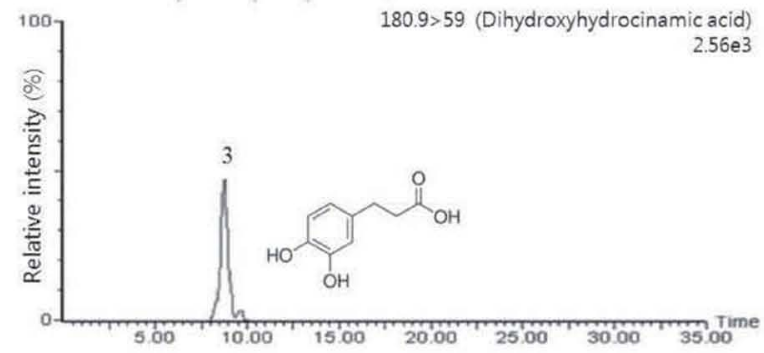

(D)

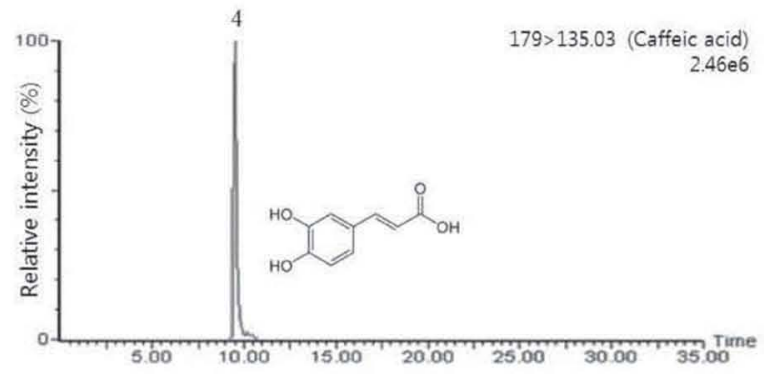

(E)

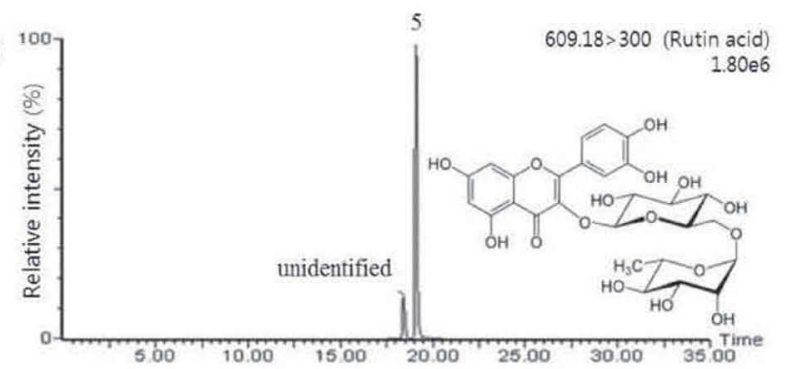

(F)

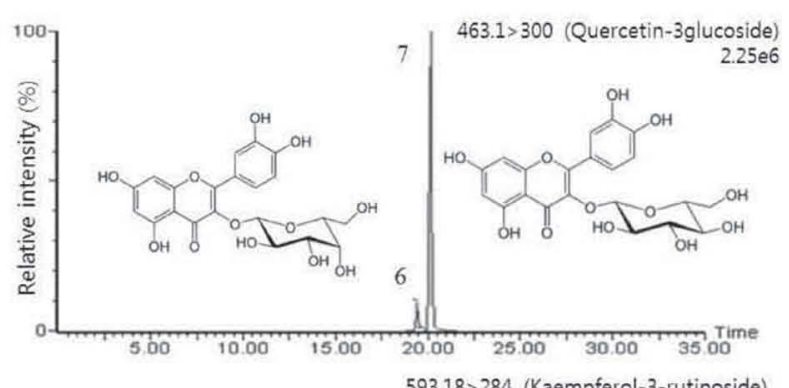

(G)

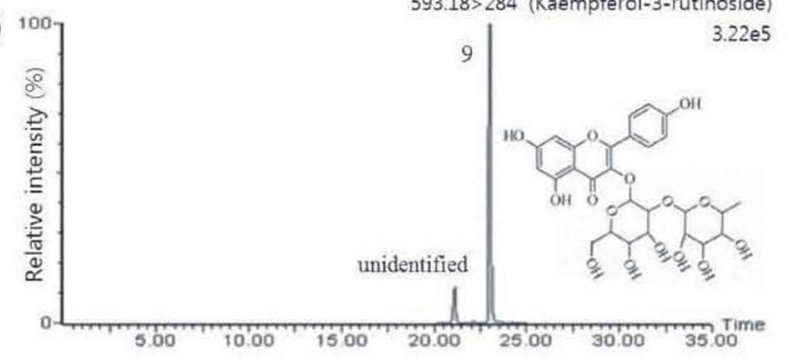

(H)

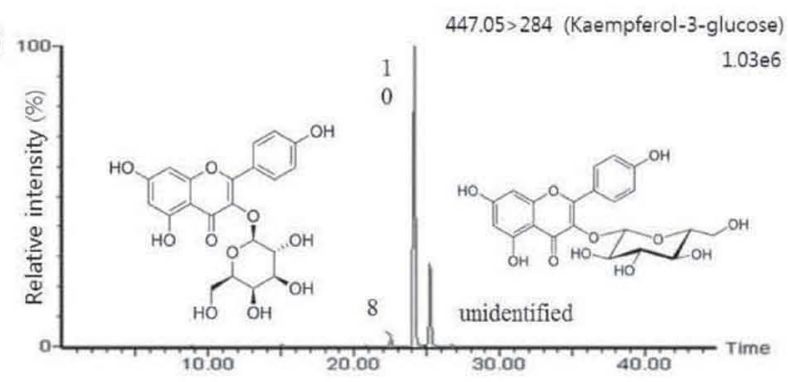

7

(I)

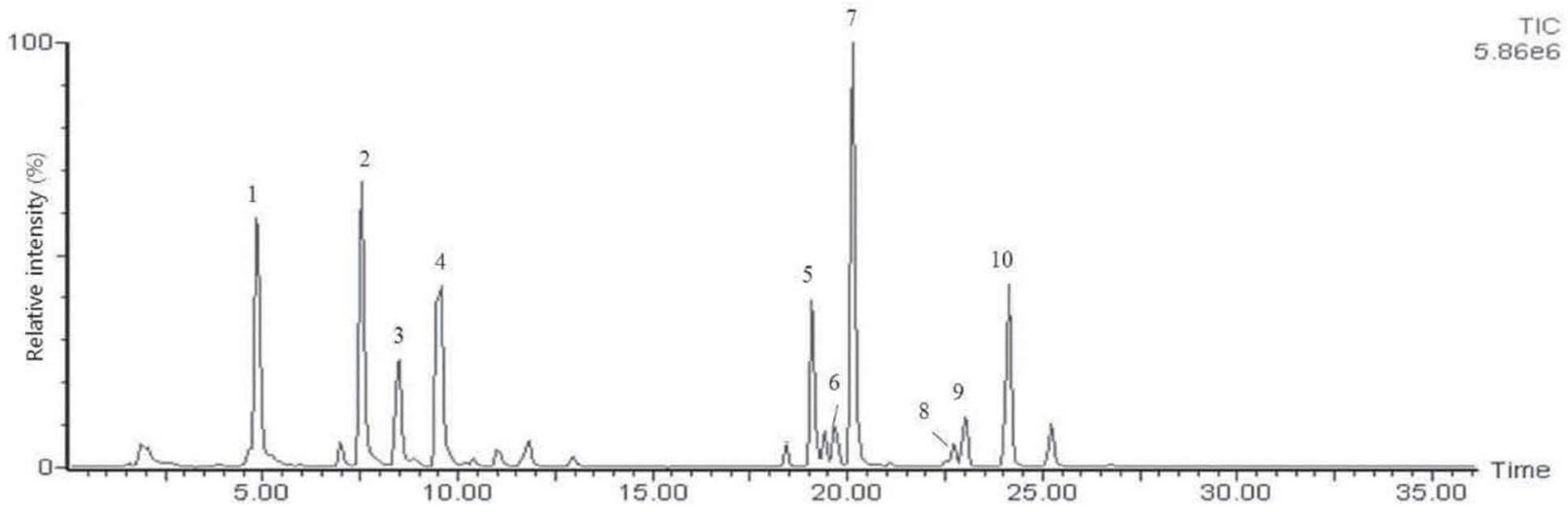

Figure 2. (A-H) Ultra-performance liquid chromatography (UPLC)-MS/MS chromatograms of phenolic compounds in Cudrania tricuspidata (CT)-supplemented yogurt. 1, Neo-chlorogenic acid; 2, chlorogenic acid; 3, 3,4-dihydroxyhydrocinnamic acid; 4, caffeic acid; 5, rutin hydrate; 6, quercetin-3-galactoside; 7, quercetin-3-glucoside; 8, kaempferol-3-galactoside; 9, kaempferol-3-rutinoside; 10, kaempferol-3-glucoside. (I) UPLC-MS total ion current chromatograms of phenolic compounds of CT supplemented yogurt. TIC = total ion chromatograms. 


\section{(A)}

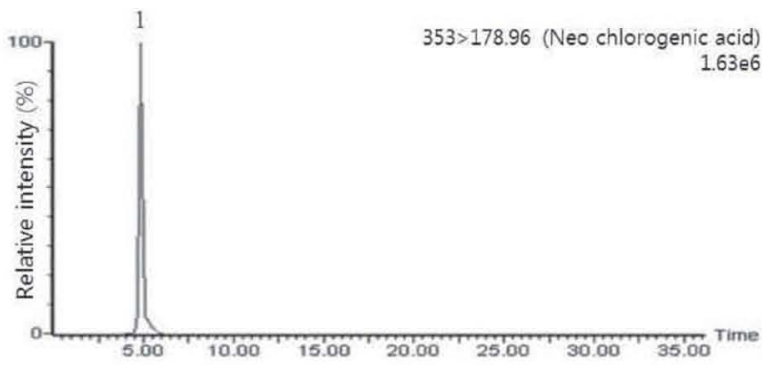

(B)

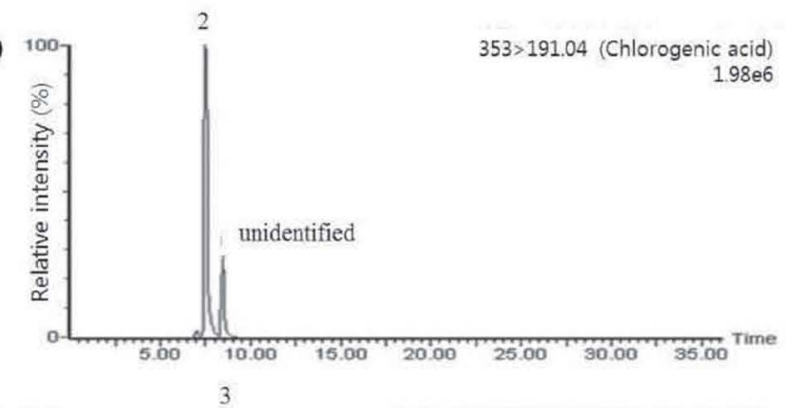

(C)

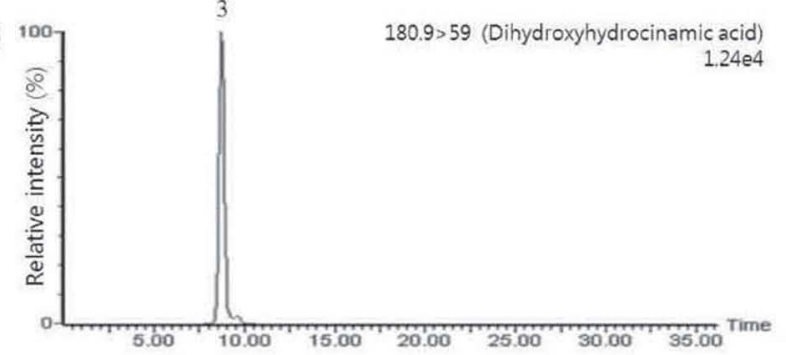

(D)

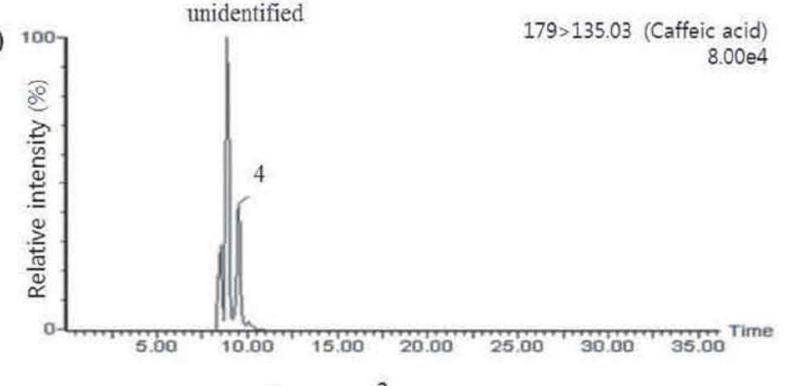

(E)

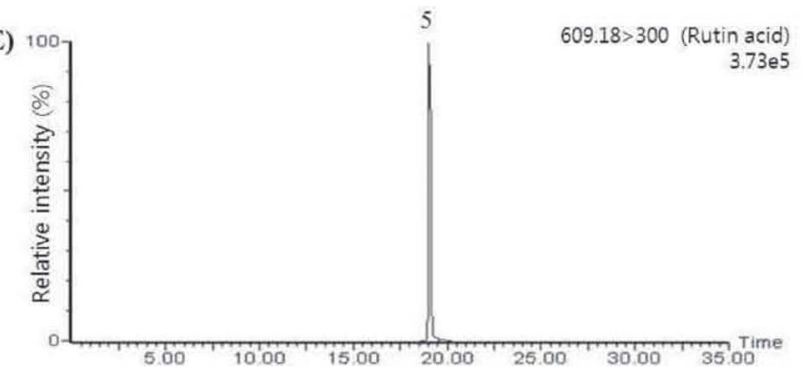

(F)

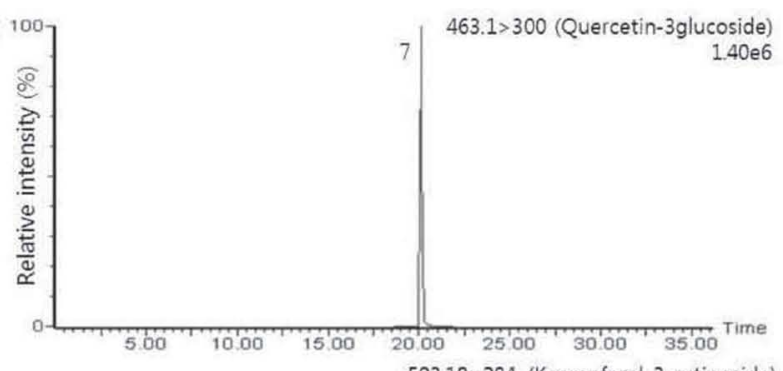

(G)

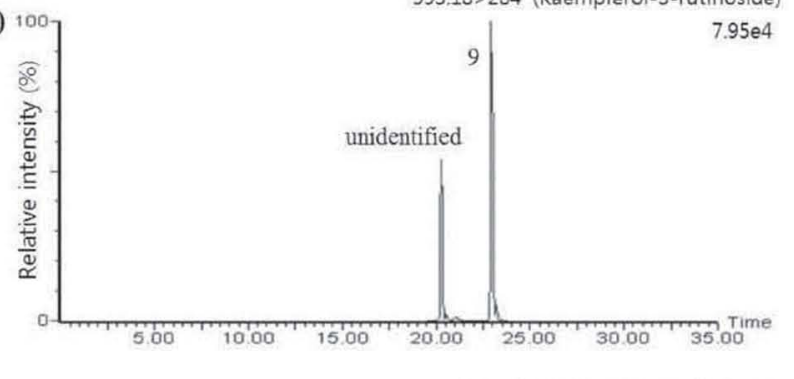

(H) ${ }^{1}$

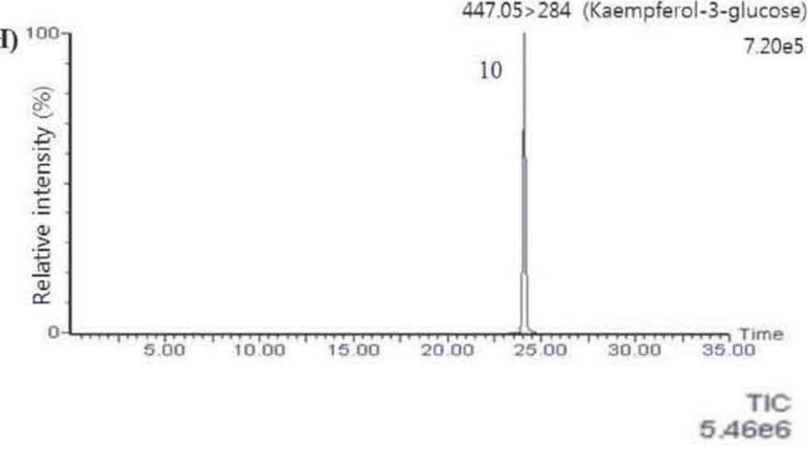

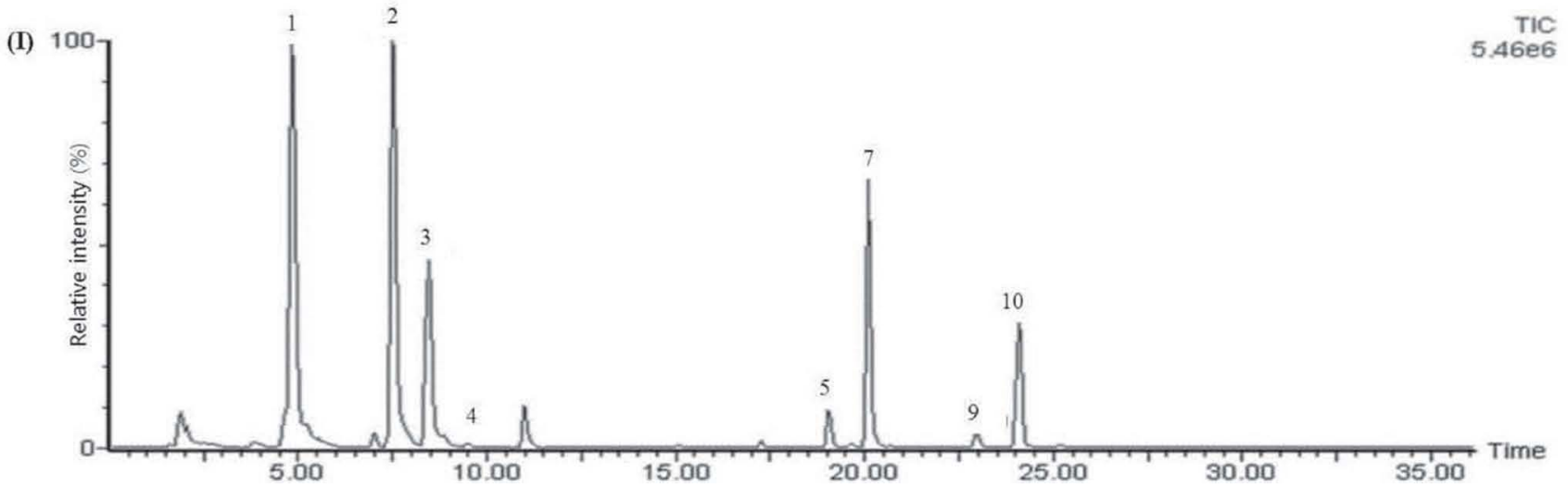

Figure 3. (A-H) Ultra-performance liquid chromatography (UPLC)-MS/MS chromatograms of phenolic compounds in Morus alba-supplemented yogurt (MA). 1, neo-chlorogenic acid; 2, chlorogenic acid; 3, 3,4-dihydroxyhydrocinnamic acid; 4, caffeic acid; 5, rutin hydrate; 7, quercetin-3-glucoside; 9, kaempferol-3-rutinoside; 10, kaempferol-3-glucoside. (I) UPLC-MS total ion current chromatograms of phenolic compounds of MA-supplemented yogurt. TIC $=$ total ion chromatograms. 
Table 4. Identification of phenolic compounds by ultra-performance liquid chromatography-MS/MS

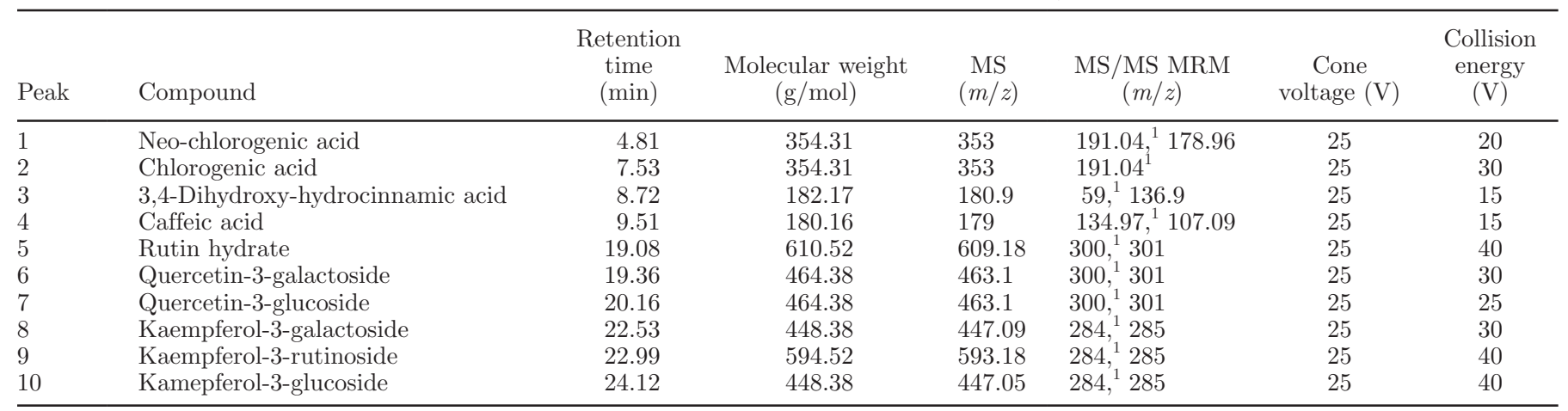

${ }^{1} \mathrm{MS} / \mathrm{MS}$ multiple reaction monitoring (MRM) used for the quantification of each standard.

of the different fermentation model system and short fermentation time.

In recent years, the concept of prebiotics has been developed into a more comprehensive one. Vodnar and Socaciu (2012) reported that microencapsulation of LAB with green tea extract increased the cell viability and maintained bacterial stability. Further, it has been reported that red wine polyphenol extracts and cocoa-derived flavonols modulated the human gut microbiota, indicating that these natural polyphenols have prebiotic potential (Queipo-Ortuño et al., 2012). Based on these results, phenolic compounds in plant extracts might have affected the MA- and CT-mediated enhancement of yogurt processing parameters, such as acidification kinetics and viability of starter bacteria.

Additionally, CT and MA contained a variety of phenolic compounds, and the prominent compound was neo-chlorogenic acid followed by chlorogenic acid in both yogurt samples. The concentrations of flavonoids such as quercetin-3-glucoside and rutin hydrate
$(6.15 \pm 0.32 \mu \mathrm{g} / \mathrm{g}$ and $5.69 \pm 0.04 \mu \mathrm{g} / \mathrm{g}$, respectively) were significantly higher in the CT-supplemented than in the MA-supplemented yogurt. The total phenolic compounds in the CT-supplemented yogurt were higher than that in the MA-supplemented yogurt (30.42 \pm $0.06 \mu \mathrm{g} / \mathrm{g}$ and $24.24 \pm 0.03 \mu \mathrm{g} / \mathrm{g}$, respectively). This result suggested that the CT-supplemented yogurt had higher antioxidant activity than the MA-supplemented yogurt, which was confirmed by ferric-reducing antioxidant power (FRAP), DPPH, and ABTS measurements (Figure 4). It has been reported that $\mathrm{CT}$ and MA are used in a traditional plant remedy, because of their high content of phytochemicals such as phenolic acids and flavonoids, which are beneficial for health. Moreover, extracts of leaves of these herbs exhibited higher antioxidant activities than those of other parts (e.g., stems, roots, and fruits; Jeong et al., 2009). Our results indicated that these compounds are important factors contributing to antioxidant activity of the yogurts.

Table 5. Phenolic compounds contents of the yogurts supplemented with the plant extracts ${ }^{1}$

\begin{tabular}{|c|c|c|c|c|}
\hline \multirow[b]{2}{*}{ Compound } & \multicolumn{2}{|c|}{$\mathrm{CT}$} & \multicolumn{2}{|c|}{ MA } \\
\hline & $\begin{array}{c}\text { Before fermentation } \\
(\mu \mathrm{g} / \mathrm{g})\end{array}$ & $\begin{array}{l}\text { After fermentation } \\
\qquad(\mu \mathrm{g} / \mathrm{g})\end{array}$ & $\begin{array}{c}\text { Before fermentation } \\
(\mu \mathrm{g} / \mathrm{g})\end{array}$ & $\begin{array}{c}\text { After fermentation } \\
(\mu \mathrm{g} / \mathrm{g})\end{array}$ \\
\hline Chlorogenic acid & $5.16 \pm 0.01^{\mathrm{a}}$ & $4.84 \pm 0.03^{\mathrm{b}}$ & $7.21 \pm 0.52^{\mathrm{a}}$ & $6.37 \pm 0.47^{\mathrm{a}}$ \\
\hline 3,4-Dihydroxy-hydrocinnamic acid & $0.005 \pm 0.00^{\mathrm{b}}$ & $0.025 \pm 0.01^{\mathrm{a}}$ & $0.17 \pm 0.01^{\mathrm{b}}$ & $0.26 \pm 0.02^{\mathrm{a}}$ \\
\hline Caffeic acid & $4.35 \pm 0.10^{\mathrm{a}}$ & $3.30 \pm 0.09^{\mathrm{a}}$ & $0.040 \pm 0.01^{\mathrm{a}}$ & $0.035 \pm 0.00^{\mathrm{b}}$ \\
\hline Quercetin-3-glucoside & $6.59 \pm 0.28^{\mathrm{a}}$ & $6.15 \pm 0.32^{\mathrm{b}}$ & $3.49 \pm 0.28^{\mathrm{a}}$ & $3.44 \pm 0.33^{\mathrm{a}}$ \\
\hline Kaempferol-3-galactoside & $0.10 \pm 0.00^{\mathrm{a}}$ & $0.082 \pm 0.01^{\mathrm{a}}$ & ND & ND \\
\hline Kaempferol-3-rutinoside & $1.68 \pm 0.06^{\mathrm{a}}$ & $1.55 \pm 0.02^{\mathrm{b}}$ & $0.43 \pm 0.05^{\mathrm{a}}$ & $0.34 \pm 0.04^{\mathrm{b}}$ \\
\hline Kamepferol-3-glucoside & $2.31 \pm 0.04^{\mathrm{a}}$ & $1.99 \pm 0.09^{\mathrm{b}}$ & $1.33 \pm 0.13^{\mathrm{a}}$ & $1.36 \pm 0.17^{\mathrm{a}}$ \\
\hline Total phenolic compounds & $33.02 \pm 0.04^{\mathrm{a}}$ & $30.42 \pm 0.06^{\mathrm{b}}$ & $24.73 \pm 0.33^{\mathrm{a}}$ & $24.24 \pm 0.03^{\mathrm{b}}$ \\
\hline
\end{tabular}

\footnotetext{
${ }_{\mathrm{a}, \mathrm{b}}$ Different letters indicate statistically significant differences between samples taken before and after fermentation $(P \leq 0.05)$.

${ }^{1}$ Values are presented as the mean $\pm \mathrm{SD}(\mathrm{n}=3)$. ND $=$ not detected. CT $=$ Cudrania tricuspidata-supplemented yogurt; MA $=$ Morus albasupplemented yogurt.
} 


\section{Determination of Antioxidant Activity}

The TPC in the yogurts with plant extracts was significantly higher than that in control yogurt both after fermentation and during cold storage (Figure 4A). The TPC gradually increased for all yogurts during storage, with the exception of the CT-supplemented yogurt. Nevertheless, the CT-supplemented yogurt still showed the highest TPC $(104.4 \pm 2.1 \mu \mathrm{g}$ of $\mathrm{GAE} / \mathrm{mL})$, followed by MA-supplemented yogurt $(103.7 \pm 0.6 \mu \mathrm{g}$ of GAE/ $\mathrm{mL}$ ). The fluctuations in TPC may be explained by the action of microbes and indigenous phytochemical compounds in the plant extracts during refrigerated storage
(Dalling, 1986). Microbial utilization of phenolic acids during fermentation and postacidification can lead to the production of other phenolic acids such as vanillic and $p$-hydroxybenzoic acids before the aromatic ring structure is broken down (Blum, 1998). Moreover, the decomposition of milk protein by the yogurt microbes might also contribute to the increased TPC, because the AA tyrosine, for instance, has a phenolic side chain (Shah, 2000).

The antioxidant activities of the yogurts as determined by 3 assays with different mechanisms are shown in Figures 4B to 4D. Although antioxidant activities showed slight fluctuations during the $28 \mathrm{~d}$ of storage,
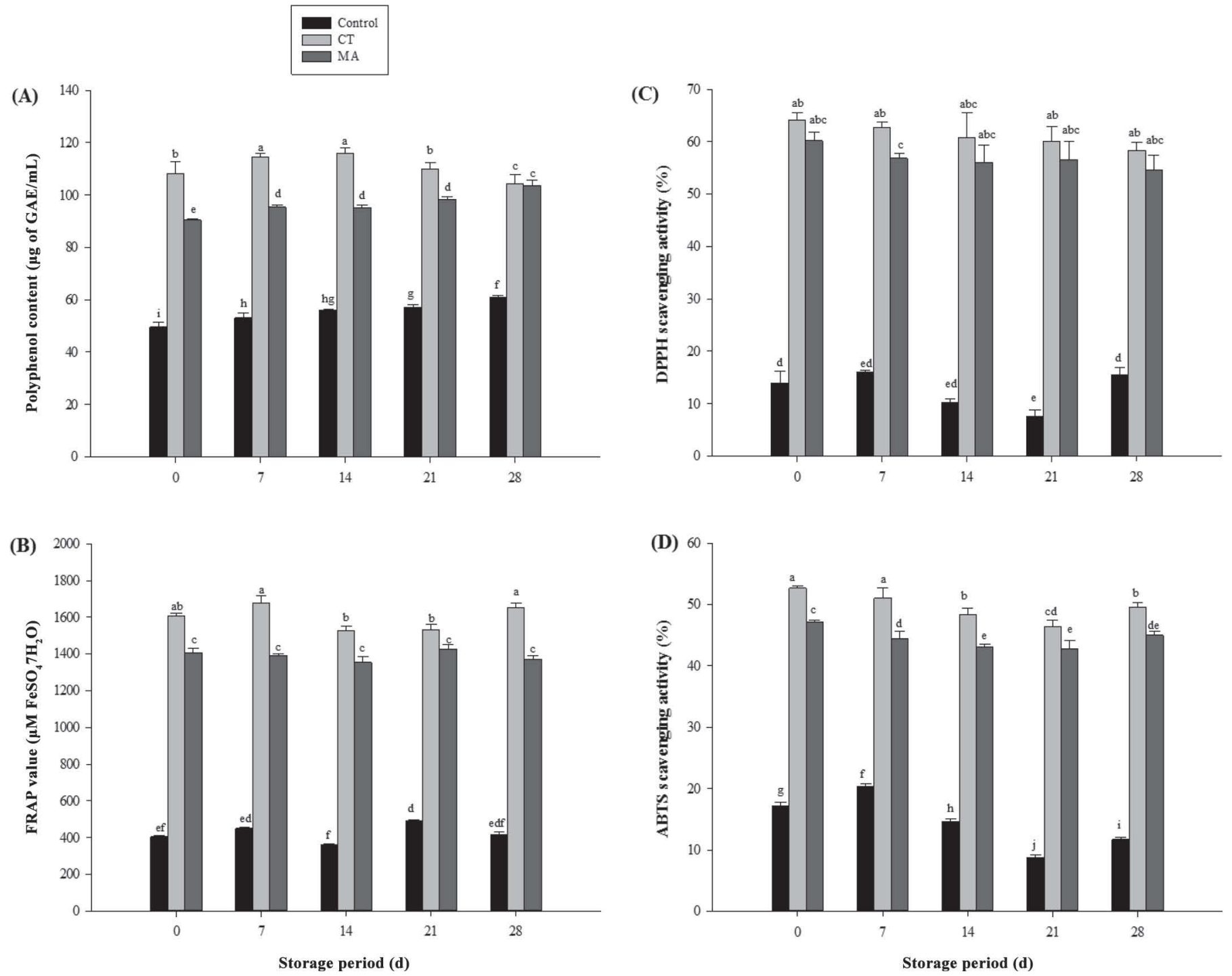

Figure 4. Total phenolic content (A), ferric-reducing antioxidant power (FRAP) value (B), 1,1-diphenyl-2-picrylhydrazyl (DPPH) radial scavenging activity (C), and 2,2'-azino-bis(3-ethylbenzothiazoline-6-sulfonic acid) diammonium salt (ABTS) radical scavenging activity (D) of the yogurts supplemented with the plant extracts during refrigerated $\left(4^{\circ} \mathrm{C}\right)$ storage. The results are presented as the mean $\pm \mathrm{SD}(\mathrm{n}=3)$. Different letters indicate statistically significant differences among the different groups $(P<0.05)$. CT $=$ Cudrania tricuspidata-supplemented yogurt; MA = Morus alba-supplemented yogurt. 
the yogurts with plant extracts had significantly higher activities than control yogurt in all 3 antioxidant tests. At the end of storage, supplemented yogurts showed antioxidant activities approximately 2.4 to 4.4 times greater than that of control yogurt, depending on the extract. In particular, CT yogurt had the greatest antioxidant activity. Moreover, the yogurts with plant extracts maintained greater antioxidant activity during cold storage. In this study, the yogurts supplemented with plant extracts were characterized by high TPC. According to Velioglu et al. (1998) and Thompson et al. (2007), the higher antioxidant activities of yogurts by addition of plant extracts were most likely a result of the phytochemical contents of plant extracts and microbial metabolic activities. Continued microbial growth during storage may have altered some of the phenolic compounds, and hence, increased antioxidant activities (Blum, 1998). Consequently, the consumption of yogurt supplemented with plant extracts has potential health benefits associated with high antioxidant activity and live bacterial content.

\section{CONCLUSIONS}

Supplementation of plant extracts as prebiotics obviously decreased the fermentation time and increased the viability of the yogurt starter cultures when compared with control yogurt. Fructose and glucose in the plant extracts were used as energy sources by the starter cultures. In addition, fortification of yogurt with the plant extracts also led to an increase in lactic acid and pyruvic acid contents and a decrease in formic acid and propionic acid contents. Formic acid functioned to enhance the growth of LAB. Moreover, hydroxycinnamic acid, such as neo-chlorogenic, chlorogenic, and caffeic acid, in the plant extracts was degraded and metabolized during yogurt fermentation, which might be attributed to the fermentation properties of the plant extract-supplemented yogurts. Further, substantially higher antioxidant activities were observed for the yogurts with plant extracts than for nonsupplemented yogurt, concomitant with higher TPC. The improved fermentation and antioxidant properties of the yogurts were related to the phenolic compounds in $\mathrm{CT}$ and MA extracts; especially, CT-supplemented yogurts showed the greatest antioxidant activities. Therefore, the addition of CT extract to yogurt has the potential to be further developed for consumers as a functional yogurt with antioxidant properties.

\section{ACKNOWLEDGMENTS}

This research was supported by the Basic Science Research Program through the National Research Founda- tion of Korea (NRF), funded by the Ministry of Education (2014R1A1A2008481) and the High Value-Added Food Technology Development Program of the Korea Institute of Planning and Evaluation for Technology in Food, Agriculture, Forestry, and Fisheries (iPET), and the Ministry for Food, Agriculture, Forestry, and Fisheries of Republic of Korea (313036-03-2-SB010).

\section{REFERENCES}

Adhikari, K., I. Grun, A. Mustapha, and L. Fernando. 2002. Changes in the profile of organic acids in plain set and stirred yogurts during manufacture and refrigerated storage. J. Food Qual. 25:435-452.

Adolfsson, O., S. N. Meydani, and R. M. Russell. 2004. Yogurt and gut function. Am. J. Clin. Nutr. 80:245-256.

Amirdivani, S., and A. S. Baba. 2011. Changes in yogurt fermentation characteristics, and antioxidant potential and in vitro inhibition of angiotensin-1 converting enzyme upon the inclusion of peppermint, dill and basil. LWT Food Sci. Technol. 44:1458-1464.

Amoroso, M., M. M. De Nadra, and G. Oliver. 1989. The growth and sugar utilization by Lactobacillus delbrueckii ssp. bulgaricus and Streptococcus salivarius ssp. thermophilus isolated from market yogurt. Lait 69:519-528.

AOAC International. 2012. Official Methods of Analysis. 19th ed AOAC Int., Gaithersburg, MD.

Bajpai, V. K., A. Sharma, and K. H. Baek. 2013. Antibacterial mode of action of Cudrania tricuspidata fruit essential oil, affecting membrane permeability and surface characteristics of food-borne pathogens. Food Contr. 32:582-590.

Blum, U. 1998. Effects of microbial utilization of phenolic acids and their phenolic acid breakdown products on allelopathic interactions. J. Chem. Ecol. 24:685-708.

Bruno, F. A., W. E. V. Lankaputhra, and N. P. Shah. 2002. Growth, viability and activity of Bifidobacterium spp. in skim milk containing prebiotics. J. Food Sci. 67:2740-2744.

Cha, J. Y., H. J. Kim, B. S. Jun, S. S. Bin, and Y. S. Cho. 2000. Effects of water-soluble extract from leaves of Morus alba and $\mathrm{Cu}$ drania tricuspidata on the lipid peroxidation in tissues of rats. J. Korean Soc. Food Sci. Nutr. 27:32-33.

Couteau, D., A. McCartney, G. Gibson, G. Williamson, and C. Faulds. 2001. Isolation and characterization of human colonic bacteria able to hydrolyse chlorogenic acid. J. Appl. Microbiol. 90:873-881.

Dalling, M. J. 1986. Plant Proteolytic Enzymes. Vol. 1 and 2. CRC Press, Boca Raton, FL.

Donkor, O., A. Henriksson, T. Vasiljevic, and N. P. Shah. 2005. Probiotic strains as starter cultures improve angiotensin-converting enzyme inhibitory activity in soy yogurt. J. Food Sci. 70:m375-m381.

Jaya, S., and H. Das. 2004. Effect of maltodextrin, glycerol monostearate and tricalcium phosphate on vacuum dried mango powder properties. J. Food Eng. 63:125-134.

Jeong, C.-H., G. N. Choi, J. H. Kim, J. H. Kwak, H. J. Heo, K.-H. Shim, B.-R. Cho, Y.-I. Bae, and J.-S. Choi. 2009. In vitro antioxidative activities and phenolic composition of hot water extract from different parts of Cudrania tricuspidata. J. Food Sci. Nutr. $14: 283-289$.

Katsube, T., Y. Tsurunaga, M. Sugiyama, T. Furuno, and Y. Yamasaki. 2009. Effect of air-drying temperature on antioxidant capacity and stability of polyphenolic compounds in mulberry (Morus alba L.) leaves. Food Chem. 113:964-969.

Maksimović, Z., D. Malencic, and N. Kovacevic. 2005. Polyphenol contents and antioxidant activity of Maydis stigma extracts. Bioresour. Technol. 96:873-877.

Manning, T. S., and G. R. Gibson. 2004. Prebiotics. Best Pract. Res. Clin. Gastroenterol. 18:287-298.

Oh, N. S., H. A. Lee, J. Y. Lee, J. Y. Joung, K. B. Lee, Y. Kim, K. W. Lee, and S. H. Kim. 2013. The dual effects of Maillard reaction and enzymatic hydrolysis on the antioxidant activity of milk proteins. J. Dairy Sci. 96:4899-4911. 
Oliveira, R. P., A. C. Florence, R. C. Silva, P. Perego, A. Converti, L. A. Gioielli, and M. N. Oliveira. 2009. Effect of different prebiotics on the fermentation kinetics, probiotic survival and fatty acids profiles in nonfat symbiotic fermented milk. Int. J. Food Microbiol. 128:467-472.

Park, K. H., Y.-D. Park, J.-M. Han, K.-R. Im, B. W. Lee, I. Y. Jeong, T.-S. Jeong, and W. S. Lee. 2006. Anti-atherosclerotic and antiinflammatory activities of catecholic xanthones and flavonoids isolated from Cudrania tricuspidata. Bioorg. Med. Chem. Lett. 16:5580-5583.

Peng, Y., D. S. Horne, and J. A. Lucey. 2009. Impact of preacidification of milk and fermentation time on the properties of yogurt. J. Dairy Sci. 92:2977-2990.

Queipo-Ortuño, M. I., M. Boto-Ordóñez, M. Murri, J. M. Gomez-Zumaquero, M. Clemente-Postigo, R. Estruch, F. C. Diaz, C. AndrésLacueva, and F. J. Tinahones. 2012. Influence of red wine polyphenols and ethanol on the gut microbiota ecology and biochemical biomarkers. Am. J. Clin. Nutr. 95:1323-1334.

Ravula, R. R., and N. P. Shah. 1998. Selective enumeration of Lactobacillus casei from yogurts and fermented milk drinks. Biotechnol. Tech. 12:819-822.

Rechner, A. R., M. A. Smith, G. Kuhnle, G. R. Gibson, E. S. Debnam, S. K. S. Srai, K. P. Moore, and C. A. Rice-Evans. 2004. Colonic metabolism of dietary polyphenols: Influence of structure on microbial fermentation products. Free Radic. Biol. Med. 36:212-225.
Roginski, H., J. W. Fuquay, and P. F. Fox. 2003. Encyclopedia of Dairy Sciences. Volumes 1-4. Academic Press, London, UK.

Shah, N. P. 2000. Effects of milk-derived bioactives: An overview. Br. J. Nutr. 84:3-10.

Srivastava, S., R. Kapoor, A. Thathola, and R. P. Srivastava. 2006. Nutritional quality of leaves of some genotypes of mulberry (Morus alba). Int. J. Food Sci. Nutr. 57:305-313.

Tharmaraj, N., and N. Shah. 2003. Selective enumeration of Lactobacillus delbrueckii ssp. bulgaricus, Streptococcus thermophilus, Lactobacillus acidophilus, bifidobacteria, Lactobacillus casei, Lactobacillus rhamnosus, and propionibacteria. J. Dairy Sci. 86:2288-2296.

Thompson, J. L., K. Lopetcharat, and M. A. Drake. 2007. Preferences for commercial strawberry drinkable yogurts among African American, Caucasian, and Hispanic consumers in the United States. J. Dairy Sci. 90:4974-4987.

Vedamuthu, E. R. 1977. Exotic fermented dairy foods. J. Food Prot. 40:801-802.

Velioglu, Y. S., G. Mazza, L. Gao, and B. D. Oomah. 1998. Antioxidant activity and total phenolics in selected fruits, vegetables, and grain produces. J. Agric. Food Chem. 46:4113-4117.

Vodnar, D. C., and C. Socaciu. 2012. Green tea increases the survival vield of Bifidobacteria in simulated gastrointestinal environment and during refrigerated conditions. Chem. Cent. J. 6:61. 